Article

\title{
Synthesis of a Metal Ion Adsorbent from Banana Fibers and Its Adsorption Properties for Rare Metal Ions
}

\author{
Tetsuto KAJIYAMA ${ }^{1 *}$, Shohei SAKAI ${ }^{2}$, Jun INOUE ${ }^{1}$, Toru YOSHINO ${ }^{3}$, Satoshi OHMURO ${ }^{2 * *}$, \\ Kensuke $\mathrm{ARAI}^{4}$ and Hisao KOKUSEN ${ }^{2}$
}

\author{
${ }^{1} J o n a n$ Branch, Regional Technology Support Division, Commercialization Support Development, \\ Tokyo Metropolitan Industrial Technology Research Institute, 1-20-20 Minamikamata, Ota, Tokyo 144-0035, Japan \\ ${ }^{2}$ Department of Chemistry, Tokyo Gakugei University, 4-1-1 Nukuikitamachi, Koganei, Tokyo 184-0015, Japan \\ ${ }^{3}$ Environment Technology Group, Division II, Research and Development Department, \\ Tokyo Metropolitan Industrial Technology Research Institute, 2-4-10 Aomi, Koto, Tokyo 135-0064, Japan \\ ${ }^{4}$ Division of Physical and Analytical Chemistry, Nihon Pharmaceutical University, \\ 10281 Komuro, Ina, Kitaadachi, Saitama 362-0806, Japan
}

(Manuscript received March 31, 2016; accepted August 31, 2016)

\begin{abstract}
The synthesis of metal ion adsorbents from modified banana fibers comprising a Schiff base was investigated. The adsorption properties of a metal ion adsorbent were evaluated, and banana fiber (BF)-g-(glycidyl methacrylate)(GMA)(BFGMA) were synthesized. A Schiff base 2,2'-\{iminobis[ethane-2,1-diylnitrilo(E)methylidine]\}bisphenol was synthesized via a reaction of diethylenetriamine and 5-bromo-salicyialdehyde in methanol. A metal ion adsorbent (BF-GMA(Br)) was synthesized via a reaction of the Schiff base with BF-GMA. Over $90 \%$ of $\mathrm{La}^{3+}, \mathrm{Gd}^{3+}, \mathrm{Tm}^{3+}, \mathrm{Pr}^{3+}, \mathrm{Tb}^{3+}, \mathrm{Yb}^{3+}, \mathrm{Nd}^{3+}, \mathrm{Dy}^{3+}$, $\mathrm{Lu}^{3+}, \mathrm{Sm}^{3+}, \mathrm{Ho}^{3+}, \mathrm{Eu}^{3+}$, and $\mathrm{Er}^{3+}$ were adsorbed in a $\mathrm{pH}$ range of 6.0-6.6 by the synthesized metal ion adsorbent. Almost

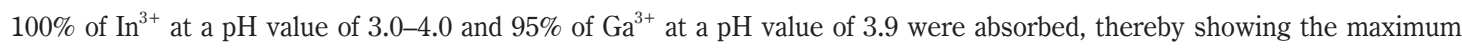
adsorption percentage. Almost $15 \%$ and $25 \%$ of $\mathrm{In}^{3+}$ was adsorbed at a $\mathrm{pH}$ value of 1.4-1.6 and 1.8, respectively. Adsorption of $\mathrm{Ga}^{3+}$ was barely observed in the $\mathrm{pH}$ range of $1.4-1.8$. These results show that banana fibers can be utilized as metal ion adsorbents.
\end{abstract}

Keywords: Banana fiber, Schiff base, Rare metal, Rare earth, Metal ion adsorbent

\section{Introduction}

In recent years, banana fibers have drawn attention as a renewable source of materials for industrial applications. Banana is an environment-friendly food material and its cultivation does not take a toll on farmlands. Therefore, effective reuse of banana fibers has been studied as a valuable biomass resource ${ }^{1,2)}$. In our previous study, banana fiber and poly(butylene succinate) composites were investigated using hexamethylene di-isocyanate as a reactive compatibilizer ${ }^{3)}$. Upon the addition of hexamethylene di-isocyanate, alkali-treated banana fibers were found to improve adhesion between banana fibers and poly(butylene succinate). Therefore, it is desirable to explore other useful characteris- tics of banana fibers.

Several methods for collecting and separating metal ions, including ion exchange and solvent extraction, have been reported. Environment-friendly ion exchange and the use of chelate materials for collection and separation of metal ions have been investigated by many researchers ${ }^{4-8)}$. Additionally, investigation of banana fibers as an adsorbent for dyes has been reported. Gupta et al. reported the use of banana fibers in the removal of malachite green dye ${ }^{9)}$. Haris and Sathasivam reported that banana fibers can be used as adsorbents for removing methyl red from aqueous solutions ${ }^{10,11}$. However, to the best of our knowledge, investigation of banana fibers (or chemically modified banana fibers) as

\footnotetext{
* Corresponding Author E-mail: kajiyama.tetsuto@iri-tokyo.jp

** Present Address: Nagoya Institute of Technology, Gokiso-cho, Showa, Nagoya 466-8555, Japan
} 
adsorbents for various metal ions has not been reported. In our recent study, adsorption of $\mathrm{Cs}$ and $\mathrm{Sr}$ ions was studied using banana fibers as adsorbents ${ }^{12}$. The adsorption of transition metal ions using modified banana fiber has also been evaluated ${ }^{13)}$; however, the mechanism of metal ion adsorption and the metal ions has not been analyzed in detail. Thus, a re-examination of the synthetic conditions for metal ion adsorbents is necessary.

Rare metals are important in many fields of advanced materials science; moreover, their applications in material industries have significantly increased. In the present study, the synthesis of a metal ion adsorbent from modified banana fibers comprising a Schiff base was investigated in detail. In addition, adsorption properties for the rare metal ions of the metal ion adsorbent were evaluated.

\section{Experimental}

\subsection{Materials}

Banana fibers were obtained from the Republic of the Philippines. Glycidyl methacrylate (GMA), diethylenetriamine, 5-bromo-salicylaldehyde (Tokyo Chemical Industry, Co., LTD., Tokyo, Japan), di-ammonium cerium(IV) nitrate (Nakarai Tesque, INC., Kyoto, Japan), and all other chemicals were purchased and used without further purification. Deionized water was prepared by MILIPORE Elix Advantage 3 and used throughout.

\subsection{Alkali-treated banana fibers}

Banana fibers (100 g), shown in Fig. 1, were treated with $3.0 \mathrm{dm}^{3}$ of a $20-\mathrm{wt} \% \mathrm{NaOH}$ aqueous solution (aq) at room temperature for $2 \mathrm{~h}^{13)}$. The resulting alkali-treated banana fibers (BFs) were washed with water and dried overnight in a vacuum oven at $70^{\circ} \mathrm{C}$. Strands from the BFs were cut into 5-mm-long pieces (Fig. 2).

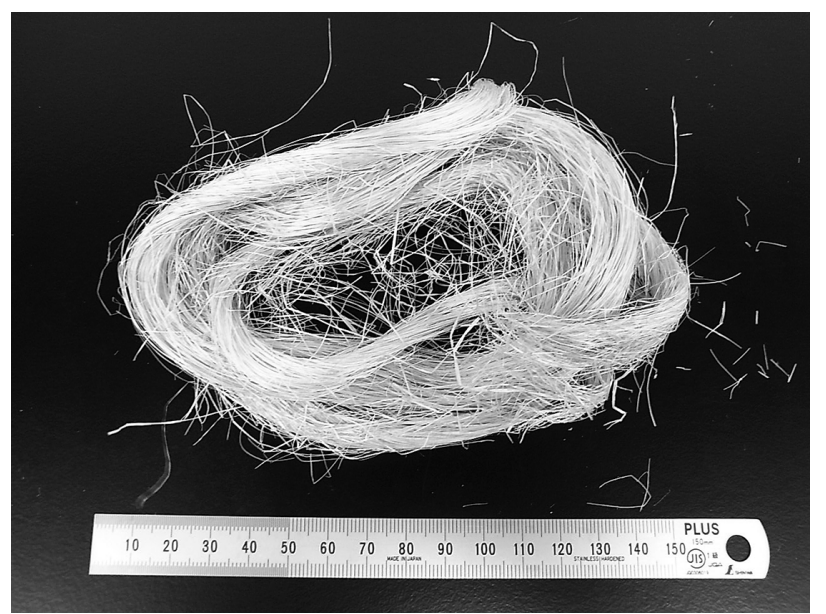

Fig. 1 Banana fibers.

\subsection{SEM Observation}

Surface morphologies of the banana fibers were observed using a scanning electron microscope (SEM).

\subsection{Synthesis of Schiff base}

A Schiff base 2,2'-\{iminobis[ethane-2,1-diylnitrilo(E) methylidine]\}bisphenol, which introduced a $-\mathrm{Br}$ group into the phenyl rings, was synthesized via a reaction of $10.3 \mathrm{~g}$ of diethylenetriamine and $40.2 \mathrm{~g}$ of 5 -bromo-salicylaldehyde at room temperature for 5 days in $1000 \mathrm{~cm}^{3}$ of methanol (Fig. 3) ${ }^{14)}$. The obtained product was a yellow powder. After washing several times with methanol, this powder was dried overnight in a vacuum oven at $50^{\circ} \mathrm{C}$. The Schiff base was identified using ${ }^{1} \mathrm{H}$ nuclear magnetic resonance (NMR)

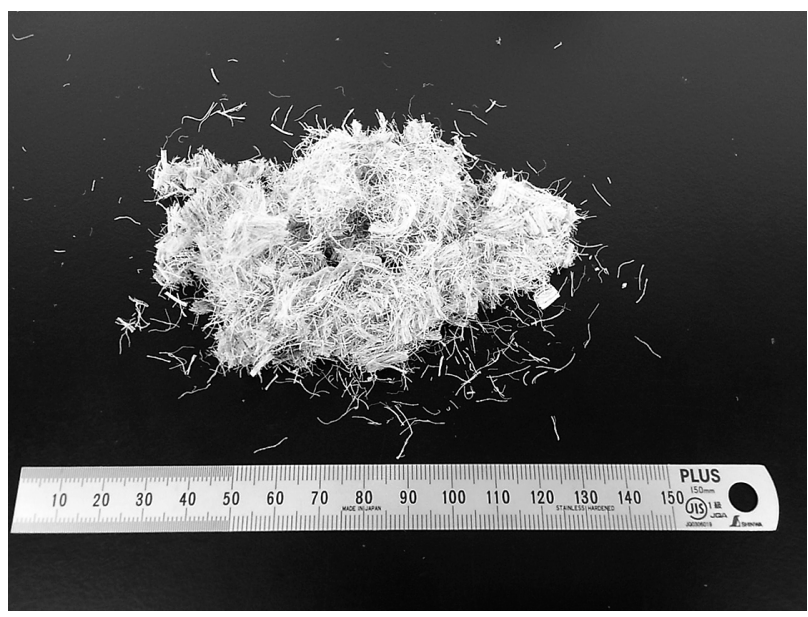

Fig. 2 Alkali-treated banana fibers. The strands of the fibers were cut into lengths of $5 \mathrm{~mm}$.

2<smiles>O=Cc1cc(Br)ccc1O</smiles><smiles>NCCNCCN</smiles>

$25^{\circ} \mathrm{C}$ $\mathrm{CH}_{3} \mathrm{OH}$<smiles>Oc1ccc(Br)cc1/C=N/CCNCC/N=C/c1cc(Br)ccc1O</smiles>

Fig. 3 Synthesis of the Schiff base. 
spectroscopy. Yield: $31.1 \mathrm{~g}$ (66.4\%); mp: $60.0-62.0^{\circ} \mathrm{C} ;{ }^{1} \mathrm{H}$ NMR (acetone- $\left.\mathrm{d}_{6}\right): 2.9 \mathrm{ppm}\left(-\mathrm{CH}_{2^{-}}, 4 \mathrm{H}\right), 3.7 \mathrm{ppm}\left(-\mathrm{CH}_{2^{-}}, 4 \mathrm{H}\right)$, $6.8 \mathrm{ppm}(-\mathrm{CH}=\mathrm{N}-, 2 \mathrm{H}), 7.4 \mathrm{ppm}-8.5 \mathrm{ppm}\left(\mathrm{C}_{6} \mathrm{H}_{3}, 6 \mathrm{H}\right)$, and $13.6 \mathrm{ppm}(-\mathrm{OH}, 2 \mathrm{H})$.

\subsection{Synthesis of banana fiber (BF)-g-(glycidyl methac- rylate)(GMA)(BF-GMA)}

Banana fiber (BF)-g-(glycidyl methacrylate)(GMA) (BF-GMA) was synthesized via a reaction of $10.0 \mathrm{~g}$ of $\mathrm{BF}$ and $4.0 \mathrm{~g}$ of glycidyl methacrylate with $0.1 \mathrm{~g}$ of di-ammonium cerium(IV) nitrate and $0.5 \mathrm{~g}$ of nitric acid at $60^{\circ} \mathrm{C}$ for $25 \mathrm{~min}$ under a nitrogen atmosphere in $200 \mathrm{~cm}^{3}$ of pure water
(Fig. 4) ${ }^{15)}$. The product was dried overnight in a vacuum oven at $70^{\circ} \mathrm{C}$, after which $13.0 \mathrm{~g}$ of BF-GMA was obtained. BF-GMA was identified using FT-IR spectroscopy. FT-IR: $1719 \mathrm{~cm}^{-1}$ (carbonyl group), $849 \mathrm{~cm}^{-1}$ (epoxide group).

\subsection{Synthesis of the metal ion adsorbent}

A metal ion adsorbent (BF-GMA(Br)), which introduced the $-\mathrm{Br}$ group onto the phenyl rings, was synthesized via a reaction of $10.0 \mathrm{~g}$ of 2,2'-\{iminobis[ethane-2,1-diylnitrilo(E) methylidine] bisphenol and $5.0 \mathrm{~g}$ of BF-GMA for 1 day in $200 \mathrm{~cm}^{3}$ of methanol (Fig. 5). The obtained material was dried overnight in a vacuum oven at $70^{\circ} \mathrm{C}$, after which $8.0 \mathrm{~g}$

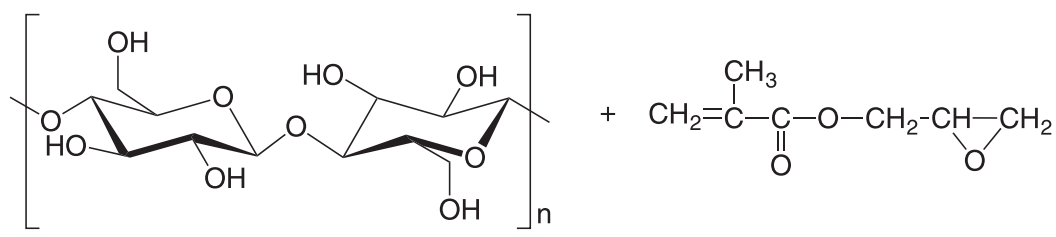

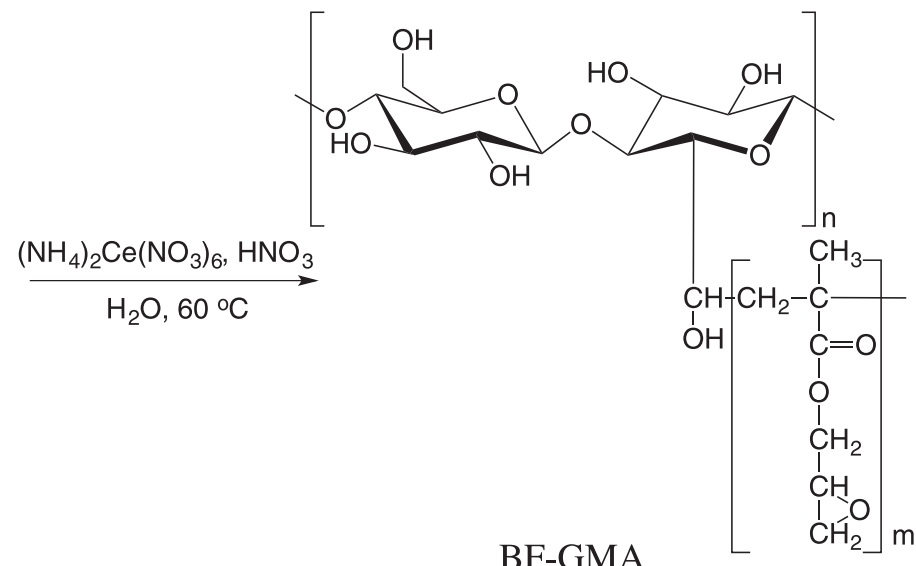

Fig. 4 Synthesis of BF-GMA.
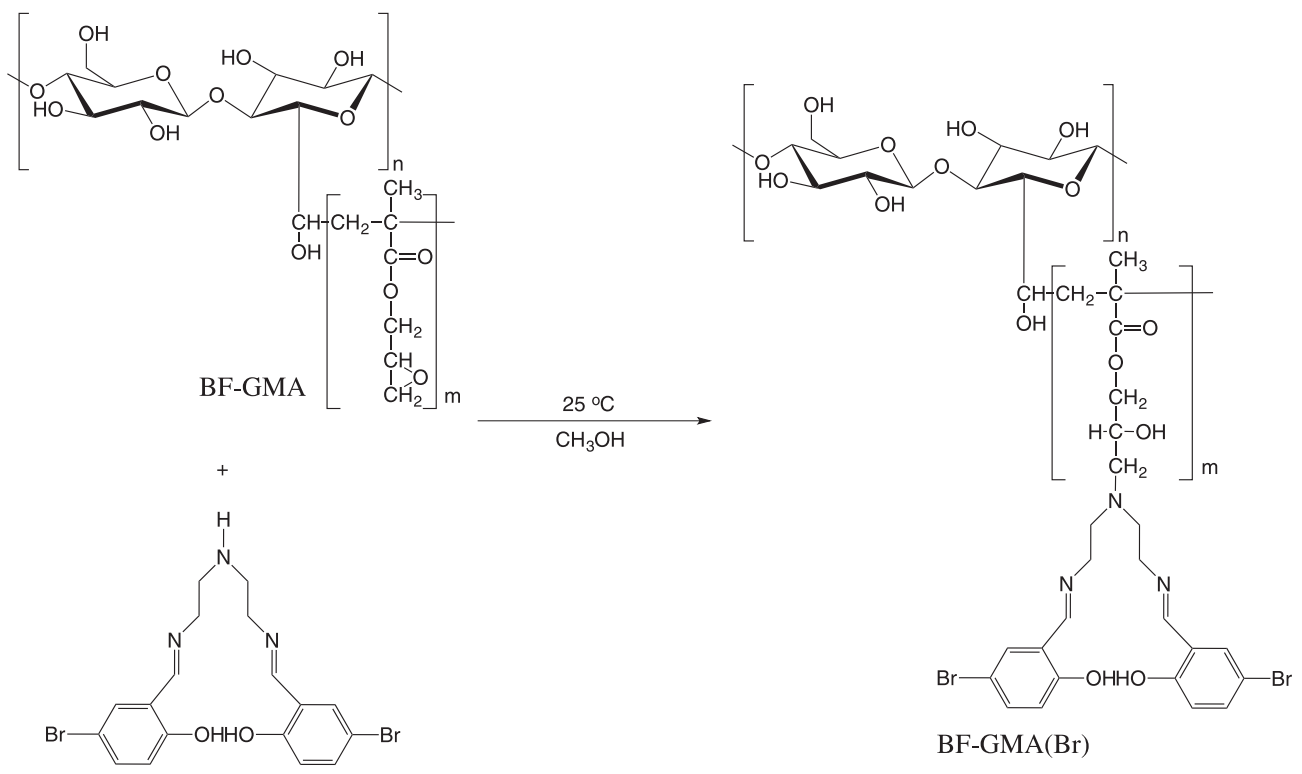

Fig. 5 Synthesis of metal ion adsorbent (BF-GMA(Br)). 
of the metal ion adsorbent was obtained. The metal ion adsorbent was identified using FT-IR spectroscopy. FT-IR: $1718 \mathrm{~cm}^{-1}$ (carbonyl group), $818 \mathrm{~cm}^{-1}$ (aromatic group).

\subsection{Adsorption of rare-earth metal ions by the metal ion adsorbent}

Individual aqueous solutions containing $2.0 \times 10^{-5} \mathrm{~mol} \mathrm{dm}^{-3}$ of the metal ions $\mathrm{La}^{3+}, \mathrm{Gd}^{3+}, \mathrm{Tm}^{3+}, \mathrm{Pr}^{3+}, \mathrm{Tb}^{3+}, \mathrm{Yb}^{3+}, \mathrm{Nd}^{3+}$, $\mathrm{Dy}^{3+}, \mathrm{Lu}^{3+}, \mathrm{Sm}^{3+}, \mathrm{Ho}^{3+}, \mathrm{Eu}^{3+}$, and $\mathrm{Er}^{3+}$ and $1.0 \times 10^{-2} \mathrm{~mol} \mathrm{dm}^{-3}$ sodium perchlorate, $1.0 \times 10^{-2} \mathrm{~mol} \mathrm{dm}^{-3}$ acetic acid, and $1.0 \times$ $10^{-2} \mathrm{~mol} \mathrm{dm}{ }^{-3} 2$-morpholinoethanesulfonic acid monohydrate (MES) were prepared. Next, $20 \mathrm{~cm}^{3}$ of each solution with $0.2 \mathrm{~g}$ of the metal ion adsorbent was put into plastic tubes. These tubes were shaken for 14 days at room temperature. After the reaction was complete, the mixed solutions were filtered. The concentration of the metal ions was measured using an inductively coupled argon plasma atomic emission spectrometer (ICP-AES). The $\mathrm{pH}$ value of the aqueous phase was measured via a $\mathrm{pH}$ meter equipped with glass electrodes.

\subsection{Adsorption of $\mathrm{In}^{3+}$ and $\mathrm{Ga}^{3+}$ ions by the metal ion adsorbent}

Individual aqueous solutions containing $1.0 \times 10^{-4} \mathrm{~mol} \mathrm{dm}^{-3}$ of $\mathrm{In}^{3+}$ and $\mathrm{Ga}^{3+}$ ions, $1.0 \times 10^{-1} \mathrm{~mol} \mathrm{dm}{ }^{-3}$ of sodium perchlorate, and $1.0 \times 10^{-2} \mathrm{~mol} \mathrm{dm}^{-3}$ of acetic acid were prepared. A $30 \mathrm{~cm}^{3}$ aliquot of each solution with $0.3 \mathrm{~g}$ of the metal ion adsorbent was put into plastic tubes. These tubes were shaken at room temperature for five days. This reaction was performed for the purpose of comparison with a previous unpublished work of ours. After the reaction was complete, the mixed solutions were filtered. The concentration of the metal ions was then determined using ICP-AES. The $\mathrm{pH}$ value of the aqueous phase was measured via a $\mathrm{pH}$ meter equipped with glass electrodes.

\section{Results and Discussion}

\subsection{Alkali-treated banana fibers}

The SEM images of the surfaces of the banana fibers (BFs) with and without alkaline treatment are shown in Figs. 6 and 7. The BFs purchased from the Republic of the Philippines were virtually untreated. They were only washed with soap and water, leaving much of the lignin and hemicellulose intact. BFs comprise approximately 9\% lignin, 39\% hemicellulose, $43 \%$ cellulose, and many other compounds ${ }^{16,17)}$. The smooth surfaces of the banana fibers transformed into a wavy morphology after alkali-treatment; the lignin and hemicellulose that originated from the BFs were removed by this treatment. Consequently, more reactive groups that originated from the cellulose existed on the surfaces of the BFs.

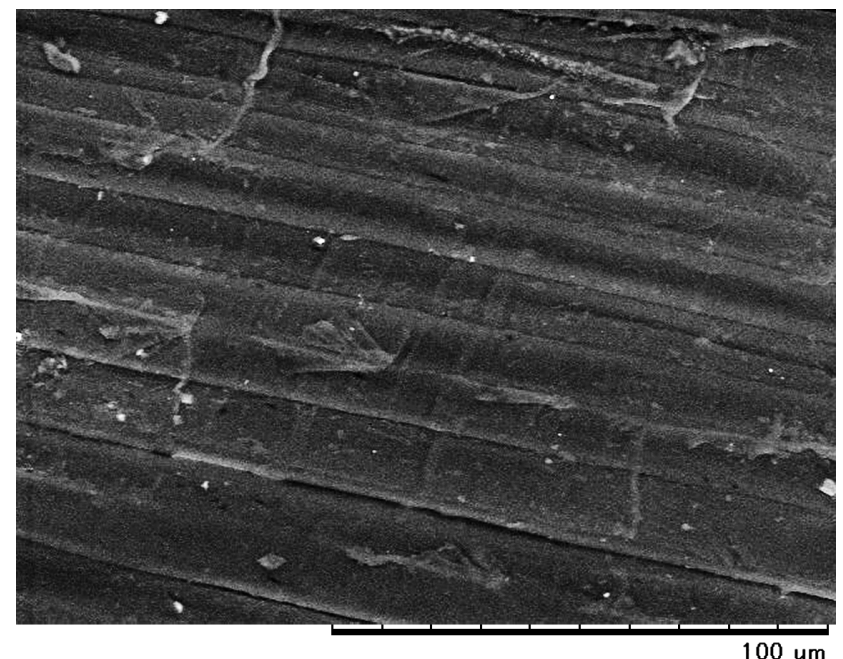

Fig. 6 SEM image of the surface of a non-alkali-treated banana fiber. Smooth surfaces on the banana fibers were observed.

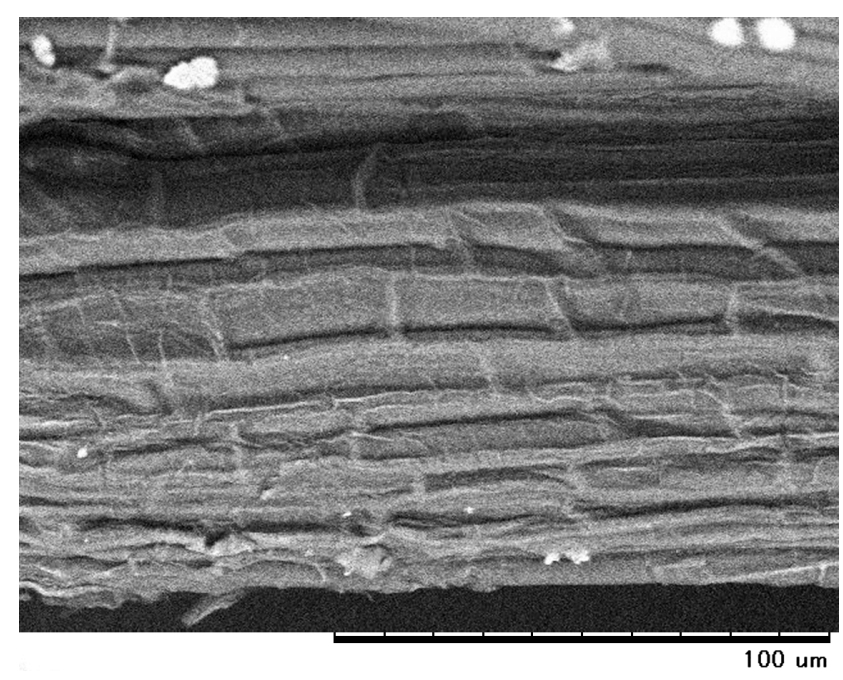

Fig. 7 SEM image of the surface of an alkali-treated banana fiber. After alkali-treatment, the smooth surfaces of the banana fibers transformed into a wavy morphology.

\subsection{Synthesis of BF-GMA(Br)}

In the present study, BF-GMA(Br) was synthesized. The monomer reaction percentage (\%) and grafting percentage (\%) were determined as:

Monomer reaction $(\%)=\frac{\left(W_{\mathrm{a}}-W_{\mathrm{b}}\right)}{W_{\mathrm{c}}} \times 100$

Grafting $(\%)=\frac{W_{\mathrm{a}}}{W_{\mathrm{b}}} \times 100$

where $W_{\mathrm{a}}$ and $W_{\mathrm{b}}$ represent the weights of the BFs after and before the grafting process, respectively. Additionally, $W_{c}$ represents the weight of the monomer (GMA). During the 


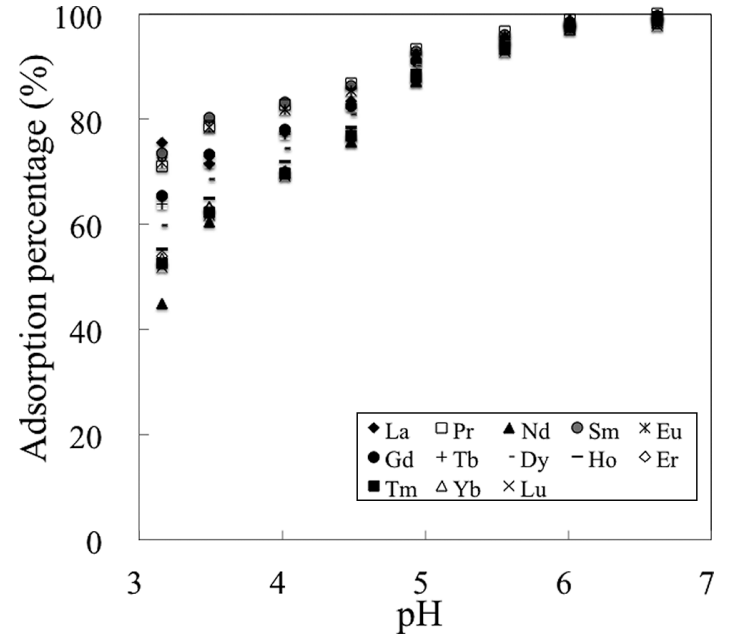

Fig. 8 Effects of pH on the adsorption of rare-earth metal ions.

synthesis of BF-GMA, the monomer reaction percentage (\%) of GMA was $75 \%$ and the grafting percentage (\%) was $130 \%$.

The reaction of the Schiff base with BF-GMA resulted in $0.3 \mathrm{~g}$ of $\mathrm{BF}-\mathrm{GMA}(\mathrm{Br})$, incorporating $2.4 \times 10^{-4}$ moles of the Shiff base.

When introducing an electron-withdrawing group such as $-\mathrm{Br}$, the acid dissociation constant of $\mathrm{BF}-\mathrm{GMA}(\mathrm{Br})$ was enhanced compared to a $-\mathrm{H}$ group or an electron-donating group such as $-\mathrm{CH}_{3}$ or $-\mathrm{OCH}_{3}$. Therefore, BF-GMA(Br) can be more readily chelated with metal ions in comparison to introduction of $\mathrm{a}-\mathrm{H}$ group or an electron-donating group such as $-\mathrm{CH}_{3}$ and $-\mathrm{OCH}_{3}{ }^{13)}$.

\subsection{Adsorption properties of BF-GMA(Br) for rare-earth metal ions}

An adsorption experiment was performed using $\mathrm{BF}-\mathrm{GMA}(\mathrm{Br})$. The adsorption percentages of the rare-earth metal ions are shown in Fig. 8. Over 90\% of the all the metal ions were adsorbed at $\mathrm{pH}$ values ranging from 6.0 to 6.6. These results demonstrate the strong possibility for utilization of banana fibers as adsorbents of rare-earth metal ions; however, the rare-earth metal ions were not separated from each other by BF-GMA(Br).

\subsection{Adsorption properties of BF-GMA(Br) for $\mathrm{In}^{3+}$ and $\mathrm{Ga}^{3+}$}

The adsorption percentages of $\mathrm{In}^{3+}$ and $\mathrm{Ga}^{3+}$ (shown in Fig. 9) increased up to a $\mathrm{pH}$ value of 3 and decreased at $\mathrm{pH}$ values higher than 4; this was probably because of hydrolysis. Approximately $20 \%$ of $\mathrm{In}^{3+}$ ions were adsorbed at $\mathrm{pH}$ values below 1.9; however, no $\mathrm{Ga}^{3+}$ was adsorbed up to this point, indicating the possibility that $\operatorname{In}^{3+}$ can be separated from $\mathrm{Ga}^{3+}$ using this method. Although the adsorption percentage

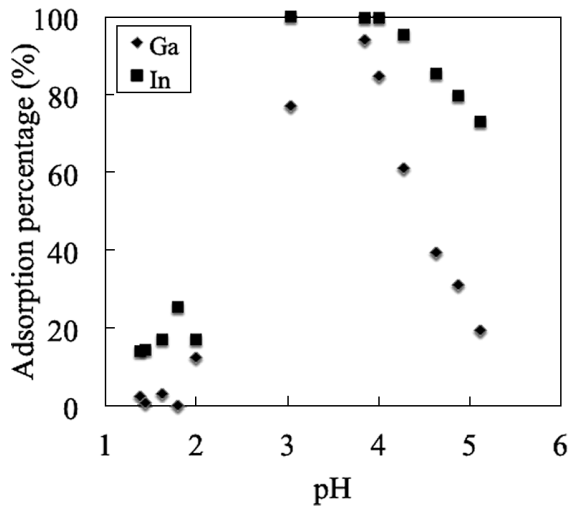

Fig. 9 Effects of $\mathrm{pH}$ on the adsorption of $\ln ^{3+}$ and $\mathrm{Ga}^{3+}$ ions.

of $\mathrm{In}^{3+}$ was not significant at these $\mathrm{pH}$ values, increasing the number of GMA chains and the amount Schiff base may improve $\mathrm{In}^{3+}$ adsorption.

\section{Conclusion}

Over $90 \%$ of $\mathrm{La}^{3+}, \mathrm{Gd}^{3+}, \mathrm{Tm}^{3+}, \mathrm{Pr}^{3+}, \mathrm{Tb}^{3+}, \mathrm{Yb}^{3+}, \mathrm{Nd}^{3+}, \mathrm{Dy}^{3+}$, $\mathrm{Lu}^{3+}, \mathrm{Sm}^{3+}, \mathrm{Ho}^{3+}, \mathrm{Eu}^{3+}$, and $\mathrm{Er}^{3+}$ were adsorbed at $\mathrm{pH}$ values of 6.0-6.6 using BF-GMA(Br).

Almost $100 \%$ of $\mathrm{In}^{3+}$ was adsorbed at $\mathrm{pH}$ values of 3.0-4.0, and $95 \%$ of $\mathrm{Ga}^{3+}$ was adsorbed at a $\mathrm{pH}$ value of 3.9 ; these are the maximum adsorption percentages obtained in this study. Almost $15 \%$ of $\mathrm{In}^{3+}$ was adsorbed at $\mathrm{pH}$ values in the range of $1.4-1.6$ and $25 \%$ was adsorbed at a $\mathrm{pH}$ value of 1.8 . Conversely, $\mathrm{Ga}^{3+}$ was barely adsorbed at these $\mathrm{pH}$ values. These results show the possibility for utilization of banana fibers as metal ion adsorbents.

\section{Acknowledgement}

This research was supported by the Environment Research and Technology Development Fund (3K143003) of the Ministry of the Environment, Japan.

\section{References}

1) R. Zuluaga, J.-L. Putaux, A. Restrepo, I. Mondragon and P. Ganan, Cellulose, 14, 585 (2007).

2) T. Yasuda and T. Kajiyama, Seikei-Kakou, 25, 592 (2013) (in Japanese).

3) T. Kajiyama, T. Yasuda, S. Mimoto, K. Shimizu, K. Hayashi, T. Yamanaka and M. Murakami, Int. Polym. Process., 28, 58 (2013).

4) K. Fujimoto, N. Tobito and S. Ito, J. Ion Exchange, 25, 12 (2014).

5) Y. Asari, N. Shoji, K. Miyoshi, D. Umeno and K. Saito, J. Ion Exchange, 22, 53 (2011).

6) S. Usada, R. Liu, Y. Wei, Y. Xu, H. Yamazaki and Y. Wakui, J. Ion Exchange, 21, 35 (2010).

7) S. Oshima, S. Hirayama, K. Kubono and H. Kokusen, J. Ion Exchange, 18, 360 (2007).

8) M. Iiyama, H. Kokusen, S. Tsurubou and Y. Komatsu, J. Ion 
Exchange, 18, 440 (2007).

9) N. Gupta, A. K. Kushwaha and M. C. Chattopadhyaya, J. Chem. Pharm. Res., 3, 284 (2011).

10) M. R. H. M. Haris and K. Sathasivam, Am. J. Appl. Sci., 6, 1690 (2009).

11) M. R. H. M. Haris and K. Sathasivam, Arch. Appl. Sci. Res., 2, 209 (2010).

12) T. Kajiyama and H. Kokusen, J. Ion Exchange, 27, 8 (2016).

13) T. Kajiyama, S. Sakai, J. Inoue and H. Kokusen, J. Ion Exchange, 25, 155 (2014).
14) L. Shi, H.-M. Ge, S.-H. Tan, H.-Q. Li, Y.-C. Song, H.-L. Zhu and R.-X. Tan, Eur. J. Med. Chem., 42, 558 (2007).

15) C. Tyagi, L.-K. Tomar and H. Singh, J. Appl. Polym. Sci., 111, 1381 (2009).

16) N. Venkateshwaran and A. Elayaperumal, J. Reinf. Plast. Comp., 29, 2387 (2010).

17) Nilza, G. J-Smith, G. Jr. Virgo and V.-E. Buchanan, Mater. Char., 59, 1273 (2008). 